\title{
Historia y Estado de Conservación de las torres Vigías y Defensivas del litoral de Murcia.
}

Recibido: 17-07-2019

\author{
BRAULIO PÉREZ LIZÁN
}

Aprobado: 25-10-2019

\section{RESUMEN}

El presente artículo realiza un análisis y estudio de las múltiples torres localizadas en las costas de la Región de Murcia utilizadas para la defensa y vigilancia de las poblaciones costeras ante posibles amenazas. Se tienen en cuenta tanto las fortificaciones construidas por los concejos municipales como aquellas de uso y propiedad privada.

Para este fin, dentro del contexto histórico que dio origen a su construcción se realiza una exhaustiva descripción de las características que debían presentar para maximizar su utilidad ante los peligros marítimos, así como las continuas reparaciones y obras que sufrieron a lo largo del tiempo hasta que las desapariciones de las amenazas provenientes del mar sumieron en el abandono y destrucción a la mayoría de ellas.

Finalmente, se presenta el análisis de los estados actuales de conservación y preservación de las fortificaciones que aún se conservan en la Región de Murcia. Con el objetivo de proteger y dar a conocer a las torres como bienes patrimoniales que deben de ser conservados y custodiados. Estas torres son tratadas como un vestigio de fenómenos pasados que no sólo afectaron a la zona litoral de Murcia, sino también a toda la costa del Mar Mediterráneo.

PALABRAS CLAVE: Torre / Corsarios / Defensa / Conservación / Patrimonio Cultural.

\section{ABSTRACT}

In this article, both the fortifications built by the local councils that governed the territory of the old Murcia and those of private use and property are analyses. Beside, these towers are located on the coastline of the Region of Murcia where they were used for the defense and surveillance of the coast in case of any threat.

For this reason, the historical context that caused the building of these defense systems, among other architectonical elements, are explained as well as the characteristics that such towers should have had in order to maximize their usefulness in case of maritime hazard. Moreover the continuous repairs and constructions that they suffered over time until the disappearance of sea threats are illustrated. 
Finally, it is important to consider the current estate of conservation and preservation of the fortifications that still survive in the Region of Murcia. In order to protect the public buildings as a cultural and heritage asset that must be preserved and protected. The towers are treated as a remnant of past event that not only affected the littoral zone of Murcia, but also all the coast of the Mediterranean sea.

KEY WORDS: Tower / Corsairs / Defence / Preservation / Heritage.

\section{Introducción}

Las torres de vigilancia fueron edificaciones de gran importancia para el control de las fronteras marítimas, pues el sentimiento natural que suponía la amenaza exterior dio la necesidad de construir elementos arquitectónicos capaces de mantener el control sobre el territorio. Es por ello que se buscaron lugares bien posicionados y seguros para la construcción de asentamientos, en los que las propias características del emplazamiento minimizaban las necesidades de construir elementos defensivos ${ }^{1}$.

Fueron construidas por toda la costa del mediterráneo, incluyendo las del antiguo Reino de Murcia durante XVI bajo Carlos V y continuadas por sus sucesores, aprovechándose en algunos casos de restos de antiguos edificios, consecuencia de la llegada y desaparición de pueblos de distinta procedencia. Siendo algunos ejemplos la torre del Rame en los Alcázares o de los Caballos en Bolnuevo². Estas construcciones son un ejemplo de los múltiples enfrentamientos con los corsarios y piratas que abundaron en estas costas y las torres que intentaron avisar y proteger a las poblaciones locales.

El objetivo principal del artículo es por tanto identificar y analizar las torres vigías dentro de la Región de Murcia, desde su creación hasta la actualidad. Para ellos

\footnotetext{
1 Plan Nacional de Arquitectura Defensiva, Instituto del Patrimonio Cultural de España, Madrid, 2012, consultado en: http://www.mecd.gob.es/planes-nacionales/planes-nacionales/arquitectura-defensiva.html, pp. $7-8$.

2 J.M. RUBIO PÁREDES, Historia de las Torres Vigías de la costa del reino de Murcia ( $\left.S^{\circ} X V I-X I X\right)$, Edición de la Real Academia Alfonso X el Sabio, Murcia, 2000,pp. 7-8.
} 
se ha recopilado la documentación tanto sobre su construcción como de las diversas restauraciones y modificaciones posteriores a su fecha de levantamiento, con el objetivo de adaptarlos a las necesidades de la época. Estudiándose además como parte fundamental de su origen el hecho histórico de los contactos y enfrentamientos con los corsarios y piratas que abundaron en estas costas.

Las historias de las torres se vieron alteradas con los cambios que se dieron en Europa, cesando su actividad y siendo la mayoría de estas destruidas o abandonadas, provocando en este último caso su deterioro y la necesidad en estos tiempos de ser intervenidas y restauradas para devolverlas a su estado original.

Así, el estudio de las actuales torres vigías y privadas nos permite conocer el panorama histórico de las costas de la Región de Murcia, desde el siglo XVI hasta el XIX. Mientras que el análisis de sus intervenciones realizadas hasta la actualidad nos muestra la importancia que estos bienes inmuebles tienen como parte del patrimonio regional y nacional y por ello deben ser protegidos.

\section{Fuentes documentales}

Con la llegada de Felipe II se tiene información acerca de la construcción de estas edificaciones en el litoral de Murcia, gracias a los documentos conservados en los archivos de varias localidades. En ellos se detallan las localizaciones, técnicas y otras necesidades para su levantamiento; siendo un documento importante la carta conservada en el Archivo Municipal de Mazarrón acerca de la visita de Juan Bautista Antonelli sobre las costas de la antigua Almazarrón para la edificación de torres. También se tienen muestras de la importancia de estas edificaciones, pues el propio monarca Felipe II envió diversas cartas indicando la necesidad deconstruirlas.

Gráficamente se conservan diversos mapas con la localización de algunas de las torres costeras siendo un ejemplo de ello, un plano de las encañizadas del Mar Menor con la torre de la Encañizada. Otro caso sería un mapa fechado en 1774 localizado en el archivo municipal de Simancas y realizado por Fermín Motanaro 
sobre las costas de Murcia, donde se visualiza una parte de la costa del sureste español, desde la torre de Águilas hasta la torre de la Horadara. También se encuentra un mapa perteneciente al pleito de la ciudad de Cartagena sobre los términos de pesca con la ciudad de Murcia realizados en 1659 y localizado en la Cancillería de Granada, donde se observan tanto las torres costeras como las de propiedad privada ${ }^{3}$.

Del mismo modo que se tiene documentación gráfica de las torres, desde los planos de su construcción hasta su situación. En el Archivo Municipal de Lorca, se localizan los alzados de la torre y de San Juan en Águilas ${ }^{4}$. En el Archivo de Murcia se tienen los planos de 1591 sobre la torre del Estacio.

A manos de ingenieros y arquitectos militares, destacamos los planos dibujados por Juan José Ordovás y reunidos en su obra: Atlas político y militar del Reyno de Murcia. Dicha publicación presenta una colección de imágenes sobre planos de edificaciones militares incluyendo las torres costeras. De Mateo Vodopich podemos encontrar algunos alzados sobre torres, por ejemplo, la torre de San Idelfonso ${ }^{5}$. Estas ilustraciones son una importante fuente de información acerca de las torres que en la actualidad han desaparecido.

La protección del patrimonio militar defensivo, y por ende de las torres de vigilancia tuvo su punto de partida a partir del año 1949 con el denominado Decreto sobre protección de los castillos. En él, el gobierno español se comprometía a proteger y custodiar todos los castillos y elementos defensivos de España. Sin embargo, fue genérico y no definía toda la amplitud del objeto a proteger, tampoco aclaraba sobre la incorporación de otros elementos defensivos junto a los castillos, tales como murallas, torres, etc ${ }^{6}$.

En 1968, el Servicio de Información Artística de la Dirección General de Bellas Artes, perteneciente al Ministerio de Educación y Ciencias, dio a conocer a

\footnotetext{
3 J. M. RUBIO PAREDES, Op. cit., pp. 48, 49, 64, 65, 66 y 70 y B. CUTILLAS VICTORIA, «Proteger y defender la Manga del Mar Menor: estudio histórico-arqueológico de la Torre de San Miguel del Estacio y la Torre de la Encañizada» en P. RODRÍGUEZ NAVARRO, (Ed) Defensive Architecture of the Mediterranean. Siglos XV y XVIII Proceedings of the International Conference on Modern Age Fortifications of the Western Mediterranean Coast Fortmed, Universidad de Politécnica de Valencia, 2015, Vol II, Op. cit., pp. 96 y 97.

4 J.GARCÍA ANTÓN, Fortificaciones en la costa de Águilas (Siglo XVI al XIX), editorial El Taller, Murcia, 1988, p. 25.

5 J. M. RUBIO PAREDES, Op. cit., pp. 102-150.

6 Plan Nacional de Arquitectura Defensiva, Op. cit., p. 4.
} 
modo decomplemento del Decreto de Protección de los Castillos del año 49 un volumen del Inventario de Protección del Patrimonio Europeo dedicado a la Arquitectura Militar. Reuniendo por primera vez un registro de la arquitectura defensiva española, con un total de 5220 monumentos en un período que abarca desde la llegada de los musulmanes a la península en el 711 hasta el 1914. El inventario era bastante esque- mático y carecía de fuentes fiables acerca de la existencia o localización de los bienes registrados en el inventario, así como su estado de conservación?

No fue hasta la entrada en vigor de la Ley 16/1985 de Patrimonio Histórico Español cuando se permitió profundizar con respecto a los bienes defensivos del estado elevándolos a Bienes de Interés Cultural. Esta ley agrupó en un sólo texto la normativa dispersa que existía otorgando nuevos criterios para la protección de los bienes, pero sin realizar una definición concreta sobre los entornos de protección ${ }^{8}$.

El desarrollo de la España de las autonomías se reflejó en la progresiva redacción de sus propias leyes de patrimonio y el desarrollo de las administraciones competentes. En el caso de la Región de Murcia no fue sino hasta el año 2007 cuando se redactó su ley de patrimonio cultural.

Además, en 1998 la Asociación Española de Amigos de los Castillos realizó un inventario de castillos y otras estructuras de carácter defensivo. Este trabajo todavía se encuentra en fase de revisión para introducirlo en la base de datos de los B.I.C. .

En el año 2006, el instituto del Patrimonio Histórico Español del Ministerio de Cultura realizó en septiembre unas jornadas técnicas sobre castillos y arquitectura defensiva española en Baños de la Encina. Una de las aportaciones de estas jornadas fue la realización de una revisión metodológica acerca de las líneas de investigación prioritarias en criterios, métodos, técnicas de conservación, restauración, estableciendo procedimientos de colaboración entre las administraciones públicas. Recogido en el documento de Carta de Baños de la Encina realizada en octubre de $2006^{10}$.

$$
\begin{aligned}
& \text { Ibídem. } \\
& \text { Ibídem. } \\
& \text { Op. cit.,p. } 5 . \\
& \text { Ibídem. }
\end{aligned}
$$


En la actualidad, y desde su redacción a partir del año 2012, el Plan Nacional de Arquitectura defensiva se constituye dentro de los objetivos marcados por IPCE en la elaboración de estos planes desde 1996 y con sus revisiones posteriores, como un instrumento no sólo teórico, sino fundamentalmente práctico a la hora de la investigación, difusión, protección, intervención y uso de técnicas de restauración específicas para estas tipologías arquitectónicas.

\section{Contexto Histórico}

Tras la ocupación a manos de los cristianos del que sería el futuro Reino de Murcia se convirtió en un territorio de diversas fronteras, amenazadas por las expediciones musulmanas provenientes del reino de Granada, de los almógavares de la Corona de Aragón, y por la piratería y guerras marítimas en sus costas. Estas últimas fueron realizadas tanto por granadinos, turcos y bereberes y posteriormente por holandeses e ingleses. Las motivaciones para el ataque a las costas del reino de Murcia se debieron a que el sureste español renace como un nuevo sector económico de importancia. Ciudades como Cartagena aprovechan el declive del comercio en aguas atlánticas debido a las guerras con Inglaterra, Holanda y Francia en el siglo XVI, emergiendo como una nueva zona comercial de gran dinamismo ${ }^{11}$.

Dicho ambiente de expansión económico favoreció la aparición de piratas y corsarios de diversas naciones, en especial turcos y bereberes, que tuvieron una actividad importante, consecuencia de la formación del reino berberisco de Argel, cuyo enfrentamiento con los reinos hispanos causaban constantes luchas marítimas. Dichos ataques provocaron que Carlos V en 1541 enviara una expedición hacía Argel, que fracasó agravando la situación en el norte de África'

Aunque presenta su repunte a partir del siglo XVI, la piratería y corsarismo no eran negocios desconocidos en aguas del Mediterráneo, pues fue una actividad

\footnotetext{
11 F. VELASCO HERNÁNDEZ, «El auge económico de Cartagena y revitalización del sureste español en los siglos XVI y XVII», Hispania: Revista Española de Historia, 2005, Vol 65, № 220, p. 496.

12 F. BRAUDEL, El mediterráneo y el mundo mediterráneo en la época de Felipe II (vol II), Fondo de cultural económica, Libraire Armand Colin, París, 1987. pp. 338-343.
} 


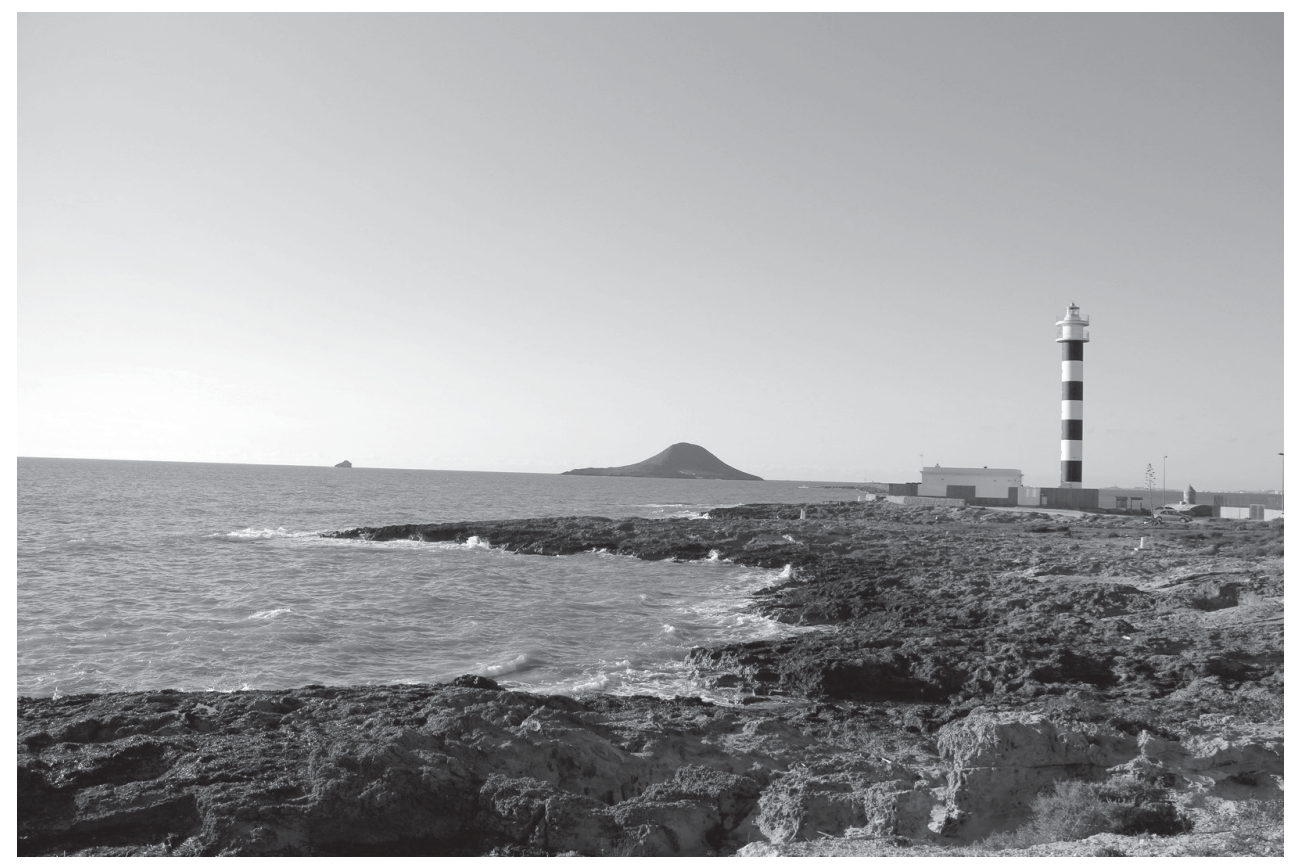

Fig. 1. Vista de la Isla Grossa desde el Estacio. Realizada por Pérez Lizán, Braulio.

que se dio desde la antigüedad y es citada por escritores tales como Homero, Boccaccio o Miguel de Cervantes. Debemos de sumarle también que, en el ambiente del Mediterráneo el uso de la palabra piratería fue poco utilizada por los españoles durante el siglo XVI, que fue sólo utilizada para las actividades realizadas por los franceses, holandeses e ingleses en el Atlántico. Utilizándose para el resto de casos el término corsario o corso. Su diferencia se encuentra en que esta última es una forma lícita de guerra, con sus pautas y normativas legalizada bien por una patente de corso o una declaración de guerra de un estado hacía otro mientras que la piratería se aleja de estas "formalidades y principios".

Las actividades de corso se justificaron bajo el pretexto de ser el Mediterráneo un mar donde chocaron dos mundos diferentes y enfrentados, el cristianismo y el islam. La sustitución de la palabra corsarios por pirata fue a partir del siglo XVII' ${ }^{13}$. 
Dichas acciones: piratería y corsarismo, propiciaron que diversas ciudades ganarán en poder y riqueza, entre las que se pueden destacar la ciudad de Argel que se convirtió en una urbe donde unos y otros no tenían impedimento ninguno en establecerse temporalmente y realizar sus reparaciones, aprovisionamientos, etc., llegando a ser una rica metrópoli ${ }^{14}$.

Como se ha mencionado anteriormente, los ataques de los corsarios fue una constante en las costas murcianas desde el siglo XV, cuando se presentan evidencias sobre diversos avistamientos y ataques a las costas de Murcia. En el año 1502 una partida corsaria desembarcó en las Algamecas de Cartagena llegando hasta laspuertas de la ciudad. En 1503 se divisaron varios navíos en las zonas de Escombreras y el puerto de Cartagena. Un año después, otra partida llegó hasta el monte de San Ginés capturando a 5 personas. En 1511 se divisó una escuadra de navíos por la isla Grossa y las costas de Cartagena ${ }^{15}$.

De gran importancia son las incursiones realizadas por corsarios como Morato-Arraez, que en 1597 logró atacar y batir varias torres, entre ellas la de San Antonio en Cabo de Palos, La Encañizada y San Miguel por la zona del Mar Menor con una flota de 8 navíos. La situación de la zona costera murciana fue tan preocupante que Jerónimo Castilla de Bobadilla, jurista y corregidor de Segovia y Guadalajara describió la zona como un lugar infestado y acosado por piratas moros y moriscos. Francisco Cascales describió la Isla Grossa como una ladronera de $\operatorname{corsarios}^{16}$.

Entre los años 1598 y 1621, se llegó a un período de paz y relajación bélica, finalizando así una etapa de conflictos desarrollados por Carlos V y Felipe II, denominada como "Pax Hispanica" de Felipe III. Pero las actividades bélicas no cesaron en las fronteras marítimas con el Islam provocando una "segunda edad de oro" del corsarismo argelino que lejos de mejorar se vieron empeoradas ${ }^{17}$. En el caso de las costas de Murcia, su situación se encontraba comprometida pues a pesar de las torres

\footnotetext{
14 Ibídem, pp. 291-292.

15 F.VELASCO HERNÁNDEZ, «La construcción de torres de defensa en el litoral de Lorca, Mazarrón y Cartagena durante el siglo XVI», Revista Murgetana, 2017, Número 136, pp. 59-60.

16 F. JIMENEZ DE GREGORIO, El Municipio de San Javier en la Historia del Mar Menor, Editorial de la Academia Alfonso X el Sabio, Murcia, 1984. Op. cit., p. 78.

17 F. VELASCO HERNÁNDEZ, «La Lucha anticorsaria en el litoral murciano», Revista de Historia Naval, Servicio de publicaciones de la Armada, Ministerio de Defensa, 2015, Número 130, Madrid, pp. 9-10.
} 
construidas con la función de avisar y proteger, no detuvieron las actividades corsarias llegan- do incluso a realizarse a plena luz del día, un ejemplo de ello fue un incidente del año 1601, cuando varios siervos de Francisco de Biembengud, capitán de Cartagena, fueron capturados ${ }^{18}$.

En 1602 aparecieron por las costas de Cartagena cinco galeotas y seis bergantinas de apoyo adueñándose del espacio litoral de cabo de Gata y la Nao, y bloqueando los puertos de Alicante y Cartagena. Dicha partida salió del Argel y se trasladó hasta la Isla de Santa Pola convirtiéndola en una base de operaciones. En ese mismo año se dio el aviso de que se acercaba una partida corsaria liderada por Morato Arraez hacía las aguas de Lorca. La respuesta de la ciudad fue enviar una partida de soldados para defender la torre del Santo Cristo como posible zona donde podían desembarcar. El resultado fue de desastre, con el deterioro de la torre y el apresamiento de numerosos soldados cristianos por parte de los hombres de Morato ${ }^{19}$.

Otra acción destacable de los piratas fue la acometida a un convoy militar provocando graves pérdidas, tanto materiales como humanas, dicho encuentro se denominó El desastre de Cabo de Palos ${ }^{20}$. En 1635, los piratas realizaron una serie de ataques que finalizaron con la ocupación de la torre de las Águilas. Años después se realizaron asaltos contra las torres de San Miguel, San Antonio y la Encañizada dejando dichas edificaciones en necesidad de ser reparadas ${ }^{21}$.

En 1645, dos fragatas berberiscas capturaron a nueve tripulantes cerca de la torre de San Miguel. En el año 1657 una partida secuestró a un grupo de marineros que llevaban municiones hacía Barcelona desde el puerto de Cartagena. Dicho secuestro se realizó sin el avistamiento de las torres ${ }^{22}$.

Fue durante el siglo XVIII cuando la intensidad de las incursiones o razzias van decreciendo, con algunos contratiempos como el ocurrido en 1758, cuando un navío mercante catalán fue defendido por la torre de San Miguel de una persecución

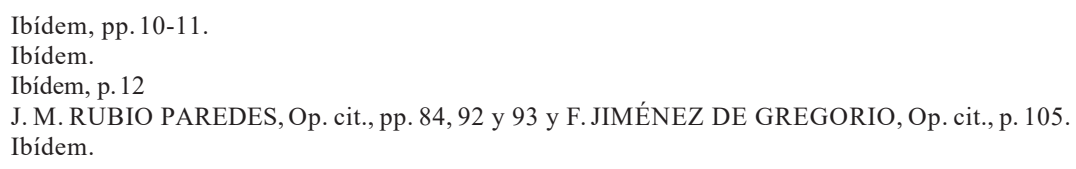


de $\operatorname{corsarios}^{23}$. Finalmente, en el siglo XIX la piratería en aguas del Mediterráneo desparece casi por completo debido a numerosos factores destacando: las mejoras de las defensas de las costas, la ocupación de las ciudades que servían de refugio para los corsarios como Argel, que cae ante las tropas francesas en 1830. Y la firma del tratado de París de 1856 que daba por ilegal el uso del corso como sistema legítimo de intervención en la $\operatorname{mar}^{24}$.

Los ataques de estos piratas y corsarios causaron numerosas incidencias y destrozos en el litoral murciano, provocando la despoblación del campo de Cartagena, Lorca y Murcia. Los atacantes no sólo secuestraban a la población, sinotambién robaban y saqueaban el ganado, productos agrícolas y provocaban daños en los centros de población.

Los corsarios solían realizar a mediados de abril y hasta noviembre unas rápidas incursiones a través de veloces navíos que ponían en tensión y alerta tanto a la población como a los vigilantes, pues podían aparecer por sorpresa y realizar breves incursiones a las costas antes de retirarse. Durante los meses de junio y hasta octubre actuaban las galeras, navíos de mayor tamaño y lentitud, con una mayor cantidadde hombres y armamento ${ }^{25}$.

\subsection{Rescate decautivos}

El rescate de prisioneros se efectuaba a través del pago de un precio. Se realizó tanto por particulares como por instituciones religiosas y civiles, con diversos modos de pago según el país y la época histórica. Durante los siglos XVI y XVII gran parte de los rescates realizados en España, Francia y Portugal fueron llevados a cabo por religiosos de las órdenes tales como las de la Trinidad y de la Merced. Ambas actuaban con pautas parecidas ya que se ponían en contacto con los piratas para solicitar

\footnotetext{
23 Ibídem, p. 144 e J. INIESTA MAGÁN, San Javier a través de sus documentos históricos (siglos XVII y XIX), Ayuntamiento de San Javier, Murcia, 1995, p. 34.

24 G. C. LÓPEZ NADAL, «El corsarismo en el Mediterráneo (1516-1830)», Piratería y corso en la Edad Moderna, XXIX Jornadas de Historia Marítima, Cuaderno monográfico del Instituto de Historia y Cultura naval, G. C. LÓPEZ NADAL (dir.), Madrid, 2004, pp. 19-20 y HERRERA ELIXABETE, Travesía por mares piratas, Trabajo Fin de Máster, Universidad del País Vasco, septiembre 2015,p. 6.

25 F. VELASCO HERNÁNDEZ, «El ataque corsario a Cabo de Palos y El Estacio en 1637», Revista Cartagena Histórica, 2008, Número 25, p. 40.
} 
la fecha para efectuar el rescate de prisioneros otorgándoles además un pasaporte para la llegada a las costas africanas sin los problemas de piratas que asolaban dichas tierras y aguas ${ }^{26}$.

La respuesta de los africanos fue normalmente positiva, pero no era seguro que se completará con todos los trámites, ni tampoco que se rescataran a todos los presos que se deseaba ya que dentro de los prisioneros existían diversas clases. Muchos esclavos morían no sólo a manos de sus captores, sino también por enfermedades debido a sus malas condiciones de vida. Si el esclavo era liberado se le devolvía a tierra para dejarlo en libertad después ${ }^{27}$.

\section{Arquitectura defensiva. Torres}

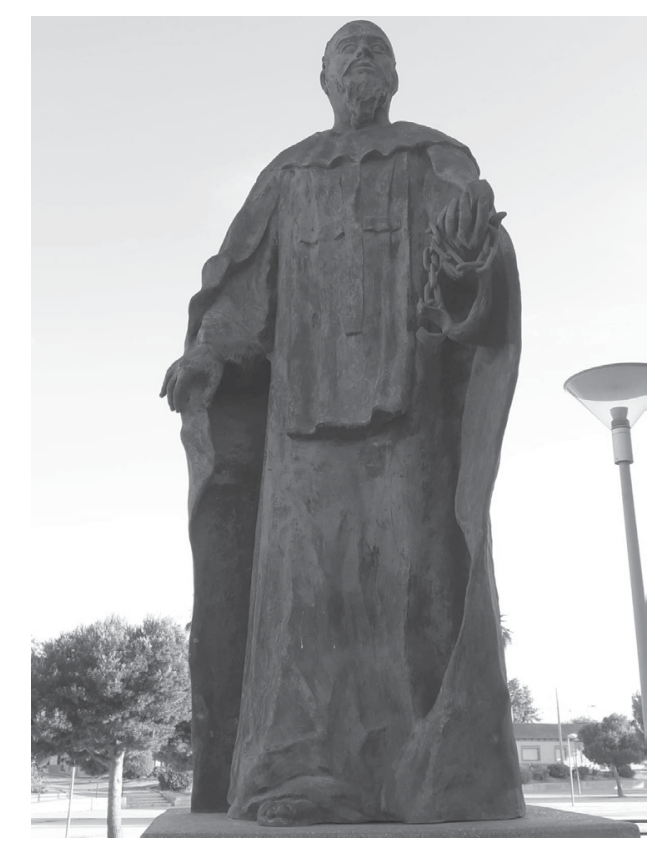

Fig. 2. Monumento dedicado a Fray Juan Gil, fraile trinitario que pagó para el rescate de Miguel de Cervantes en 1580 a manos de sus captores en Argel. 2009. Torre Pacheco. Escultura realizada por el escultor Pedro Jordán. Fotografía realizada por Braulio Pérez Lizán.

Las torres vigías son edificaciones de carácter militar construidas a lo largo de un territorio, cuya función fue la de vigilar, controlar y defender diversas partes del territorio ante la posibilidad de un ataque enemigo. Forman parte de las diversas construcciones y sistemas estratégicos ${ }^{28}$.

Por el litoral del Mediterráneo se planteó la necesidad de defender las costas, tema repetido tanto por militares, ingenieros militares, monarcas e incluso historia-

\footnotetext{
26 J. A. MARTÍNEZ TORRES, «Europa y el rescate de cautivos en el Mediterráneo durante la temprana Edad Moderna». Revista Espacio, Tiempo y Forma, Serie IV, Historia del Arte, 2005-2006, pp. 75-79. 
dores. De entre ellos podemos destacar a Felipe II por la gran cantidad de torres edificadas que construyó bajo su mandato, continuando y perfeccionando un sistema que comenzó con su padre, Carlos V; erigiéndolas no sólo por las costas de le península, sino también por territorios de Nápoles, Sicilia, Cerdeña o algunas zonas concretas del Norte de África ${ }^{29}$.

La denominación de torre se aplica por igual a las torres aisladas, almenaras o vigías, en las que se podía presentar artillería, pero de pequeño calibre ${ }^{30}$. Las formas que presentaban fueron diversas, las más comunes fueron las de base cilíndricas, cuadradas, y en menor medida, poligonales ${ }^{31}$.

La mayoría de las torres se construían sobre una base dura, donde se erigía el primer cuerpo macizo de la torre. El acceso se hacía a través de una puerta que sólo se podía acceder por una escala. El cuerpo presente podía ser de uno o varias plantas que solían estar abovedadas. El acceso a las zonas superiores se hacía por una escalera de caracol. Finalmente, las torres presentaban una azotea para situar las piezas de artillería ${ }^{32}$.

Esta tipología arquitectónica se convirtió en la mejor manera de defenderse, pues resultaba difícil de controlar todos los lugares por los que el enemigo podía aproximarse. Tal como menciona Juan Bautista Antonelli en el informe sobre las torres de la costa del Reino de Murcia, que fueron realizadas para una guerra defensiva a la qual tiene respecto el fortificar [...] pretende escusar daño como la offensiva alcançar provecho ${ }^{33}$.

Su financiación corrió a cargo de los pobladores, aquellos beneficiados directamente de la vigilancia de la torre; pagando un impuesto adicional para dichos gastos. Los sistemas de construcción fueron numerosos, pues dependían de la geografía

29 A. CÁMARA MUÑÓZ, «Las Fortificaciones y la Defensa del Mediterráneo», Sociedad Estatal para la Conmemoración de los Centenarios de Felipe II y Carlos V, Madrid, 1999, p.359.

$30 \quad$ Ibídem, pp. 360-361.

31 A. CÁMARA MUÑÓZ, «Las torres del litoral en el reinado de Felipe II: Una arquitectura para la defensa del territorio (I)» Revistas Espacio, Tiempo y Forma, Serie VII, Historia del Arte,1990, p. 61.

$32 \quad$ Ibídem, p. 59.

33 Ibídem. 
del terreno, del ingeniero y del constructor autor que trazaba la obra. Todas presentaban unas características, destacando: la adaptación a las armas de pólvora reduciendo su altura, pero con un mayor grosor, etc. Todo ello con la intención de que las nuevas edificaciones fueran más resistentes al fuego de la artillería enemiga ${ }^{34}$.

\subsection{Guarnición de lastorres}

Para la vigilancia de las fronteras a través de las torres se necesitaba de un grupo de hombres que permanecieran en sus inmediaciones y que vigilaran constantemente la costa en busca de posibles peligros. Durante los siglos XVI y XVII había destinados en cada atalaya dos paisanos pagados por el concejo dueño del edificio. A partir del XVIII fueron sustituidos por soldados de infantería y jinetes. En el caso de las torres presentaban una guarnición de un sargento denominado alcaide, y dos soldados llamados torreros ${ }^{35}$.

Castillo de Bobadilla describió sobre la organización militar de las torres de Murcia:

El alcayde está obligado a hacer guardia toda la noche [...]. Cada torre tiene seis soldados y un cabo; y cuando hay navios se da aviso a los pastores y gente del campo para que se retiren. Estos soldados no pueden salir de las torres [...] podría salir uno a dar aviso y no a otra cosa, sino que han de defenderla. Páganse estos soldados de un impuesto que hay de medio real por arroba de todo el pescadofresco ${ }^{36}$.

La eficacia de la guarnición quedó en algunos casos, gravemente desatendida o directamente no realizaban su trabajo por diversos motivos. Tal fue así que Antonio María de Bucarelli consideraba que las torres se habían convertido en elementos inútiles. Propuso diversas medidas para mejorar la situación de la guarnición; entre ellas, castigar a los que abandonan sus puestos, asignar un sueldo igual al de un soldado y establecer un número de guarniciones fijas; que serían de tres miembros para

\footnotetext{
$34 \quad$ Ibídem, p. 61.

35 J.M. RUBIO PAREDES, JOp. cit., p. 26-28.

36 J.CASTILLO DE BOBADILLA, Politica para corregidores y señores de vasallos, en tiempo de paz y de guerra y para jueces eclesiásticos y seglares, Volumen II, Imprenta Real la Gazeta, Madrid, 1775, p. 435.
} 


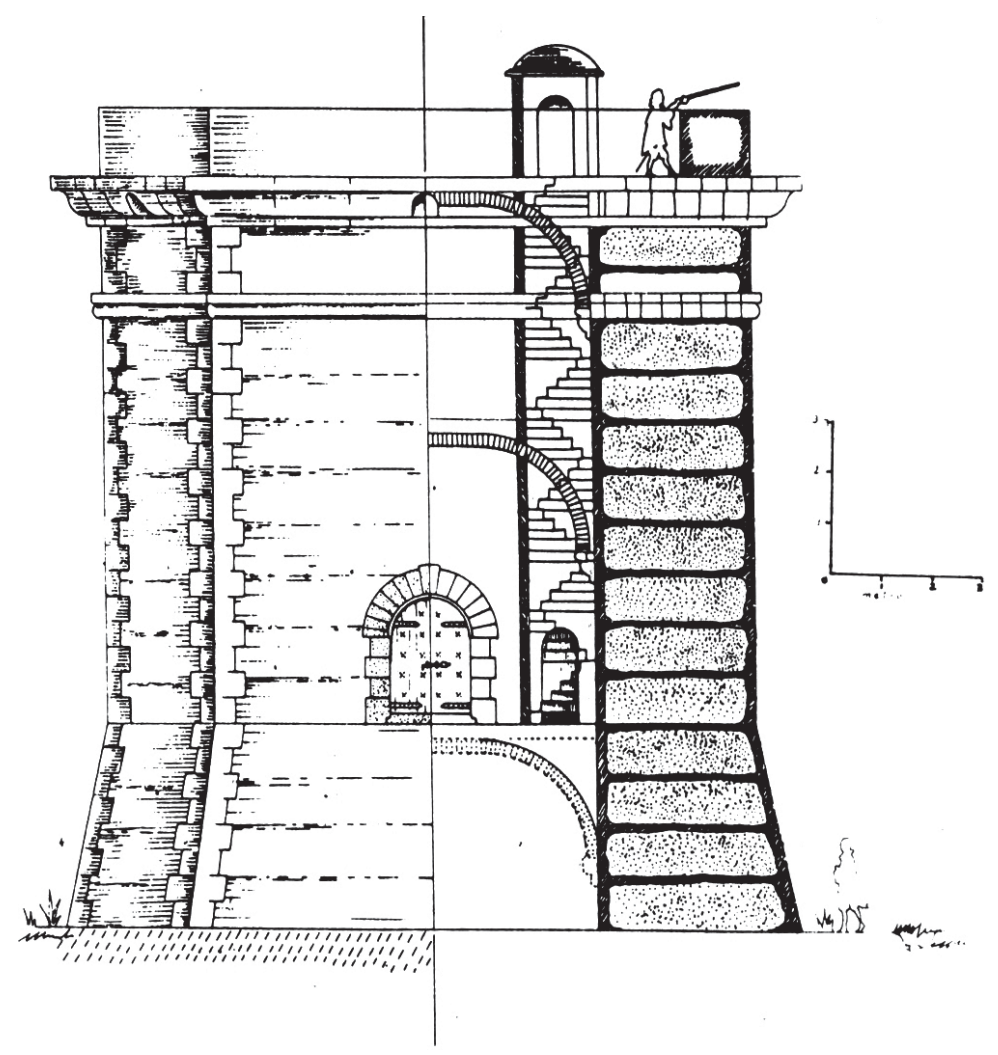

Fig. 3. Alzado y corte de la torre de San Juan de Águilas según las medidas que figuran en el proyecto de Antonelli, J. GARCÍA ANTÓN, op cit, p:21.

las atalayas y torres sin artillería y cinco para las armadas; un alcaide, dos terreros, un artillero y un guarda-almacén ${ }^{37}$.

\subsection{Sistemas de vigilancia}

Debido a que en el litoral de las costas de Murcia existían una gran variedad de recursos económicos, el territorio se convirtió en objeto de interés para corsarios y piratas, siendo necesario medidas de protección y defensa para disminuir o evitar los daños que podrían causar. 
Entre los siglos XV y XVIII las pautas tomadas fueron diversas. Se puede destacar el uso de las avanzadillas, que consistían en el establecimiento permanente de puestos de operaciones, como las ocupadas en el norte de África. Su función era servir como puntos de defensa y obtener información sobre posibles ataques que se podían preparar en las ciudades musulmanes del Norte de África como Túnez o Argel; con dicha información se podía preparar una flota para atacar los navíos enemigos o avisar sobre la llegada de estos. Otro sistema empleado para la defensa del territorio fue el despliegue de navíos armados para contrarrestar las flotas atacantes. El último sistema consistía en la construcción de un sistema de vigilancia por las costas españolas para alertar a las poblaciones sobre embarcaciones enemigas ${ }^{38}$.

\section{La construcción de torres en el Reino de Murcia}

Fue en el siglo XVI cuando la monarquía mostró preocupación por los continuos ataques realizados a las costas del reino de Murcia aprobándose varios proyectos de construcción de torres de vigilancia. Entre las que destacan las realizadas en Cabo Cope en Águilas en 1539 por orden de Carlos V y en la Encañizada en el Mar Menor, cuando ordenó al corregidor Nuño de Águila realizar un informe para localizar las mejores zonas de construcción en la Manga del Menor, planificándose a edificar otras dos torres: en el Estacio y en Cabo de Palos ${ }^{39}$.

Felipe II ordenó a Vespasiano Gonzaga Colonna, duque de Trajetto y próximo Virrey del Reino de Valencia a realizar una inspección de las costas de Valencia y Murcia para buscar los mejores lugares de edificación de puestos de vigilancia. Acompañado por el ingeniero militar Juan Bautista Antonelli, perteneciente a una familia de arquitectos e ingenieros militares de origen italiano cuya construcción más notoria fue el Castillo de Bemia o el de Santa Bárbara en Alicante. Ambos realizaron informes sobre el año 1570 tras recorrer las costas valencianas y murcianas. Antonelli propuso un plan bastante ambicioso, con la conclusión de que era necesario construir un total de 36 con un coste total de 20.200 ducados. Realizadas mediante la técnica del tapial, pues era fácil y rápido de trabajar. Aconsejaba que los trabajos se debían

\footnotetext{
$38 \quad$ Ibídem p. 19.

39 A. CÁMARA MUÑÓZ, «Las torres del litoral en el reinado de Felipe II: Una arquitectura para la defensa del territorio (II)» Revistas Espacio, Tiempo y Forma, Serie VII, Historia del Arte, 1991, p. 53.
} 


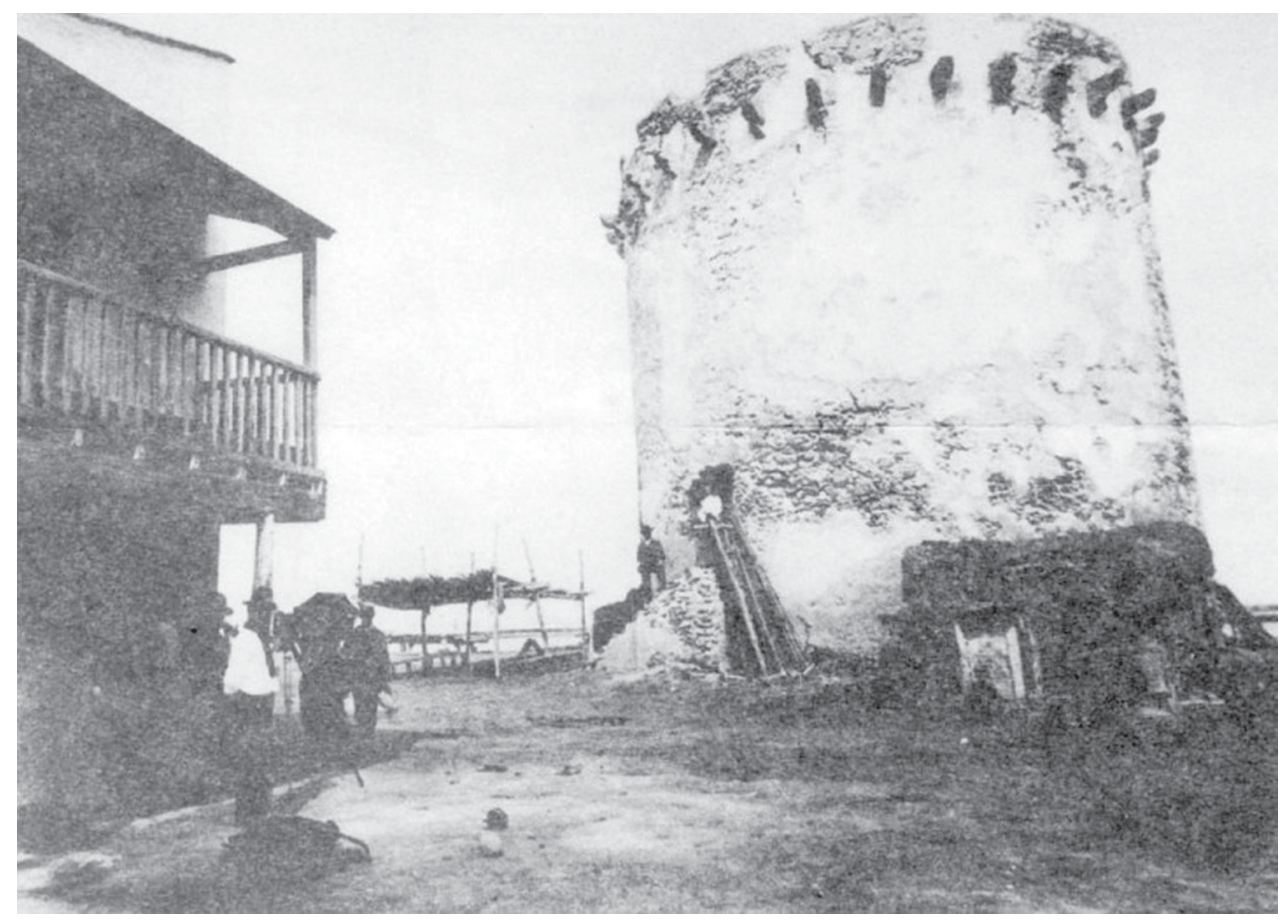

Fig. 4. Fotografía de la torre de la Encañizada, 1890. Realizada por Guirao Girada, Luis Federico. Obtenida en: http://cort.as/zY8n.

realizar entre los meses de noviembre a febrero, cuando la presencia de los corsarios eran menos frecuentes ${ }^{40}$.

Poco tiempo después, Vespasiano informó al rey sobre sus propias ideas, contrarias a las de Antonelli. Gonzaga opinaba que no era necesario realizar tantas torres; pues no impediría que los corsarios llegarán a las costas debido a la situación geográfica del litoral de Murcia, con una gran cantidad de islas y calas para esconder los navíos. Se mostró a favor de construir unas pocas torres, en zonas concretas de la Manga del Mar Menor y en la Isla Grossa. Rechazo el uso del tapial a favor de la mampostería, una técnica a base de piedra más resistente y dura que el tapial ${ }^{41}$.

40 Ibídem, pp. 54-56 y F. VELASCO HERNÁNDEZ. «Cinco torres para un reino: Los proyectos de Felipe II», Revista Cartagena Histórica, febrero, 2013, Número 39, Cartagena pp. 15-17.

41 A. CÁMARA MUÑOZ, Op. cit., pp. 54-56. 
Ambos se encontraron de acuerdo en el diseño de las torres, que debían de presentar una forma hexagonal porque de esa manera tiene las piezas mayor reculada que si fueran cuadradas y otras muchas comodidades que tienen las redondas. Debían de presentar un aljibe debajo del primer suelo, una chimenea, un habitáculo para la pólvora y dos pisos con bóveda ${ }^{42}$. Gonzaga opinaba que la guarnición debió de variar dependiendo de la cercanía de los núcleos de población.

Ambos informes fueron entregados tanto al monarca como al consejo de gue$\mathrm{rra}^{43}$. Finalmente fueron aceptadas el número de torres propuestas por Juan Bautista, pero construidas a base de mampostería y preferentemente de planta hexagonal ${ }^{44}$.

Antonelli tasó el coste de las torres: las grandes costarían un total de 700 ducados y las pequeñas sobre las 500, el pago debía realizarse con ayuda de los concejos municipales de Murcia, Lorca y Cartagena. Sin embargo, poco después de comenzar las obras surgieron diversos problemas, el primero de ellos era el coste final para la finalización de las torres resulto ser mucho mayor, aunque provocando conflictos internos y retrasos en las obras.

El Concejo de Murcia, a diferencia de los de Lorca y Cartagena, comenzó la edificación de las torres de su jurisdicción en la zona de la Manga del Mar Menor a finales del siglo XVI y principios del XVII, el origen del retraso fue debido al miedo de los trabajadores a construir por esa zona, muy frecuentada por los corsarios. Las torres construidas fueron: Torre del Pinatar y del Estacio. Presentaban una traza diferente a las dadas por Antonelli y Vespasiano, ya que su planta se realizó de forma circular y su tamaño era más pequeño al compararlo con otras torres. Fue también el siglo XVII cuando las torres en mal estado fueron reparadas a causa de los ataques marítimos ${ }^{45}$.

Durante las últimas décadas del siglo XVI y principios del siglo XVII, la función que realizaban las torres fue bastante cuestionable, pues fuentes sin fechar afirman que aunque descubran enemigos y anden por la costa los avisos que ellos dan por fuegos y ahumadas no sirven de ningún efeto para ofender los enemigos, por que estando

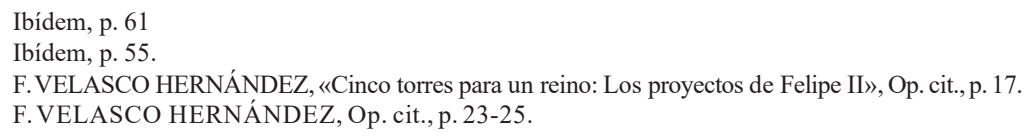


los lugares tan distintos y apartados no pueden socorrer los que andan por la costa y quando acuden esta el daño hecho, y los enemigos a salvo ${ }^{46}$.

La falta de utilidad de las torres fue de tal grado que se propuso desmantelar algunas de ellas, como por ejemplo la localizada en Cabo Cope. Otras propuestas fueron limitarlas en aquellos lugares que sirvieran para controlar amplias zonas y apoyarlas con un cuerpo de infantería, caballería y en el caso de la ciudad de Cartagena, con escuadras de galeras ${ }^{47}$. Dicho método de vigilancia y defensa fue sugerido también por el corregidor Don Pedro Zapata de Cárdenas, que se mostraba descontento y en contra del uso de las torres por ser poco eficientes, añadiendo el motivo histórico: de tiempo de Cartagineses ni Romanos que tan conbatida fue aquella costano aymemoria de aver avido torres en ella.. El problema de establecer dichos regimientos provenía del gran gasto que suponía su mantenimiento, recomendando que su pago fuera realizado a través de impuestos a la población, en especial a los moriscos. El proyecto no se llevó a cabo debido al coste de capital para su mantenimiento y la construcción y mantenimiento de las torres continuó ${ }^{48}$.

Por el siglo XVIII la gran mayoría de las torres construidas en el reino de Murcia se encontraban en servicio, y finalmente en el XIX y XX cesaron sus actividades y tuvieron diversos finales, algunas de ellas fueron destruidas debido a múltiples factores como su mal estado o la falta de interés de los gobernantes por mantenerlas de pie; siendo un ejemplo de ello la Torre del Pinatar o de la Encañizada. Otras fueron desmanteladas y reutilizados sus materiales para la construcción de otras edificaciones, como la torre del Estacio, Cabo de Palos, Portman o de San Idelfonso en Mazarrón. La mayoría de las torres que se mantienen en la actualidad fueron restauradas a finales del siglo $\mathrm{XX}$.

Las torres que se analizan a continuación responden a las variables de conservación: Esto es, han pervivido hasta la actualidad en la Región de Murcia sin que hayan perdido gran parte de su forma original, desde las restauradas y conservadas

46 A. CÁMARA MUÑOZ, Op. cit., p. 59.

47 Ibídem, p. 60.

48 J. J. RUIZ, «La Frontera de Piedra: Desarrollo de un sistema estático de defensa en la costa de Murcia (15881602)» en Actas del Congreso la Frontera Oriental Nazarí como Sujeto Histórico (S.XIII-XVI), SEGURA ARTERA, PEDRO (coord.), Lorca-Vera, Instituto de estudios almerienses, 1997, p. 659. 
en buen estado hasta las de necesidad de ser intervenidas. A su vez se dividen en dos grupos tipológicos, las construidas por los concejos y autoridades de la zona y las construidas por los miembros de la alta clase para sus terrenos.

\subsubsection{Torre de SantaHelena}

También denominada de la Azohía o de Santa Catalina. Se localiza en la parte sur de Cabo Tiñoso, y aunque localizada dentro del término de Mazarrón,pertenece de forma jurisdiccional a Cartagena.

La torre es de planta hexagonal regular de dos cuerpos más terraza, a base de mampostería de sillares y sillarejos. La base del primer cuerpo se encuentra macizado con tierras y piedras compactas, siendo la parte más ancha comparado con el resto de la torre. En el primer cuerpo se encuentra la puerta de acceso, en su cara oriental a una altura de 4.7 metros al nivel del suelo. En su interior se localizaba la chimenea $\mathrm{y}$ dos escaleras, una que daba acceso al aljibe y otra para el acceso al segundo piso.

El segundo cuerpo hay un total de 8 vanos construidos a base de tierracompactada. En el último piso se ubica la azotea con un suelo realizado a base depiedra y ladrillo macizo y rodeado por un antepecho. En ambos cuerpos se encuentran cubiertos por dos plantas abovedades de piedras y mortero de cal, comunicadas entre sí por una escalera de caracol de ladrillo ${ }^{49}$.

Su construcción data de octubre de 1578, cuando el monarca Felipe II autorizó al Concejo de Cartagena la construcción de dos torres de vigilancia entre las zonas de Cabo de Palos y la Azohía. No se tienen documentos sobre el proceso de construcción o finalización, salvo que ya se encontraba operativa por el año 1580 , pues se tiene un informe del alcaide de la torre preguntando sobre su salario correspondiente $^{50}$.

\footnotetext{
49 Ibídem, p. 119 y R. CAMPUZANO BANEGAS, Torre de Santa Elena La Azohia., Convenio comunidad autonoma-INEM,Proyecto de Restauración de Castillos de Murcia, Servicio regional de Patrimonio Histórico, 30 de marzo de 1989.

50 J. M. RUBIO PAREDES, Op. cit., p. 119
} 


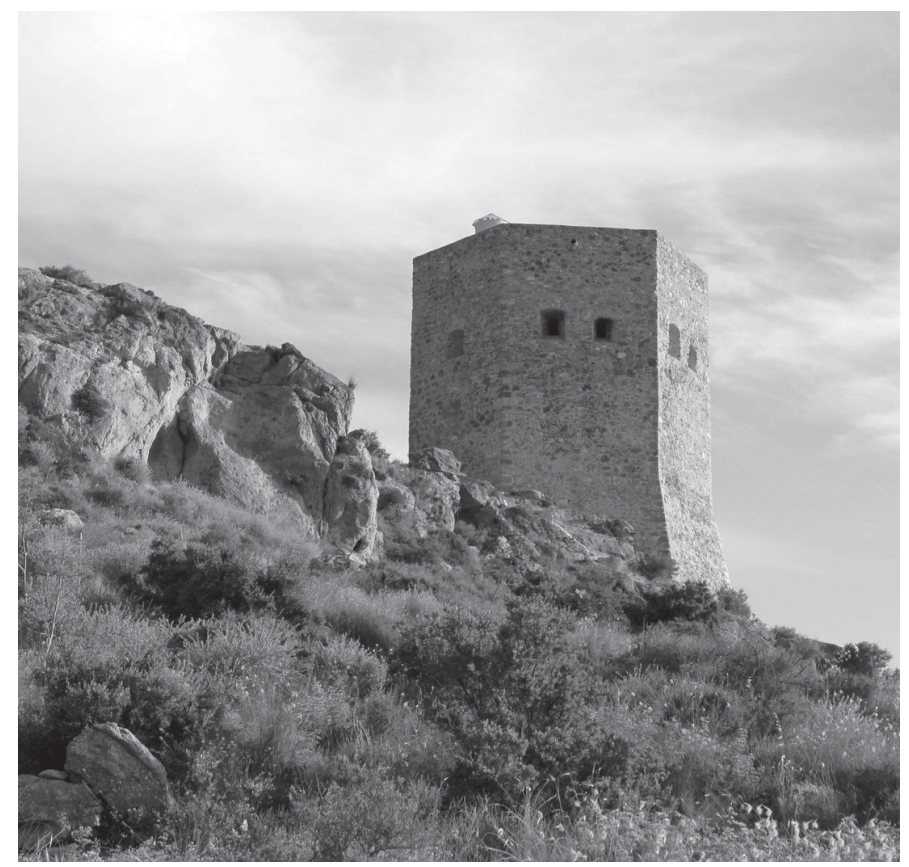

Fig. 5. Torre de Santa Helena. 1580. La Azohía (Cartagena). Realizada por Braulio Pérez Lizán.

No se vuelven a tener noticias de la construcción hasta el 9 de noviembre de 1599, fecha recogida en el libro de actas capitulares por las que el ayuntamiento de Cartagena decide acudir en auxilio a la torre de la Azohía que se encontraba bajo ataque contra tres galeotas corsarias ${ }^{51}$. Ya por el año 1614 se vuelven a tener noticias de dicha edificación cuando es citada en una carta de navegación y no se volverá a poseer más información hasta el año 1759, con el informe de Feringán Cortes sobre el estado de las torres en el reino de Murcia, destacando que se encuentra reparada, abastecida de armamento y bien defendida. Otro documento, sobre el año 1762 describe a la torre en buen estado, a falta de realizar algunas reformas en su zona oriental además de sustituir las escaleras de madera por unas de ladrillo, finalmente crítica la localización de la torre, detallando que a mayor altura su defensa y vigilancia sería más efectiva ${ }^{52}$.

51 D.GARÇÍA, Libro de actas capitulares, cabildo de19-11-1599, Archivo Municipal de Cartagena, obtenida en: http://cort.as/-JAAI.

52 Ibídem, pp. 119-120. 
En 1769 el rey pidió un informe sobre las torres de Mazarrón, acerca de su entorno y sus sistemas de comunicación con el resto de torres de la región. La petición fue realizada por Mateo Vodopich, describiendo que la torre de la Azohía se encuentra en buenas condiciones a falta de algunas reparaciones y de sustituir algunas piezas de artillería ${ }^{53}$.

Por el año 1791 se vuelve a mencionar la torre en un texto sobre torres costeras en los reinos de Valencia y Murcia, detallando que la edificación tiene una guarnición de un alcaide y dos torreros en tiempos de paz, con dos cañones de hierro y uno de bronce como armamentos principales. Con necesidad de hacer reparaciones por la zona de la artillería, el muro, la habitación de los torreros y el almacén de la pólvora, con un coste de 15665 reales $^{54}$.

Los últimos informes que se tienen de la torre como elemento defensivo datan del año 1801, con una descripción de su armamento, personal y un documento fechado en 1857 detallando que se encontraba bastante deteriorada en sus lados este, noreste y en sus interiores.

Tras la entrada en vigor de la Ley 16/85 de Patrimonio Histórico Español, la torre entra a declararse Bien de Interés Cultural, procediendo en el año 1989 a tomarse medidas de restauración y conservación junto con la torre de Cabo Cope a través del convenio de Comunidad Autónoma INEM, llevado a cabo en dos fases. En la primera fase:

- Se realizó un estudio tanto arqueológico e histórico con la intención de reunir información sobre la torre, tanto en estructura interior como en exterior, realizando además un proyecto de identificación de accesos, técnicas, materiales, etc.

- Reconstrucción de la fachada, utilizando los mismos materiales empleados en su construcción. 
- Eliminación del mortero en mal estado, seguido de la consolidación y recuperación del grosor original a base de mampostería, recuperando además los huecos de ventilación e iluminación ${ }^{55}$.

En la segunda fase:

- Se reconstruyó la parte de la bóveda derrumbada, utilizando para ello cimbras de madera, lajas de piedra con mortero de cemento que luego se descargó en el relleno de la bóveda con el fin de reducir el peso y proceder al refuerzo estructural.

- Se restauró la escalera interior, se pavimentó el nivel de la primera planta y segunda con un compuesto a base de mortero de cal lavada y con pavimentación de grava. Se desmotaron las losas de piedra de la azotea para clasificarlas mediante una relación de números con referencia a un plano, en el que aparecen la situación de cada uno de ellos.

- Construcción de una escalera de caracol para su acceso a los visitantes, resistente a las condiciones marítimas y climáticas de la zona ${ }^{56}$.

Tras las medidas realizadas entre la década de los 80 , la torre se encuentra en buen estado, tanto en su parte interior como exterior, sin falsos históricos y respetando su entorno paisajístico.

\subsubsection{Torre de SantaIsabel}

También llamada torre Vieja, del Cargador o de las Salinas. Se encuentra localizada en el Puerto de Mazarrón y presentaba como función la de controlar ellitoral y de amparar la pesca y las actividades. Sin embargo, se proyectó posteriormente la torre de San Idelfonso o torre Nueva, con una mejor situación y dejándola en un segundo plano ${ }^{57}$.

55 J. MARÍN CEBALlOS, Memorias de patrimonio: 1986- 1991: Memorias de patrimonio: intervenciones en el patrimonio Histórico de la Región de Murcia. Inmuebles, Muebles y Etnografía, $\mathrm{N}^{\circ}$ 2, Consejería de Cultura y Educación, Murcia, 1990-1992,p. 56-58.

56 Ibídem.

57 S. ALONSO NAVARRO, Libro de Castillos y Fortalezas de la Región de Murcia, Editorial Libercrom S.A, Murcia, 1990, p. 205 y VELASCO HERNÁNDEZ, FRANCISCO, «La Construcción de Torres de Defensa en el litoral», Op. cit., p. 77. 
Presenta una planta circular con una forma escarpada troncocónica de una altura de 12 metros y un grosor en sus muros de 80 centímetros. Los materiales empleados son piedra de mampostería y mortero de cal. La torre presenta un total de dos cuerpos abovedados y la cubierta. En su interior se ubica una escalera de caracol para acceder a las distintas plantas. La entrada principal se encuentra en su parte oriental a tres metros sobre el nivel del suelo ${ }^{58}$.

La torre es una de las más antiguas que se conservan en la actualidad en la Región de Murcia. Surgida con el crecimiento de las actividades marítimas a finales del siglo XV y autorizada su levantamiento en 1498. Su construcción no fue finalizada hasta bien entrado el siglo XVI, pues en una visita a zona del corregidor Juan de

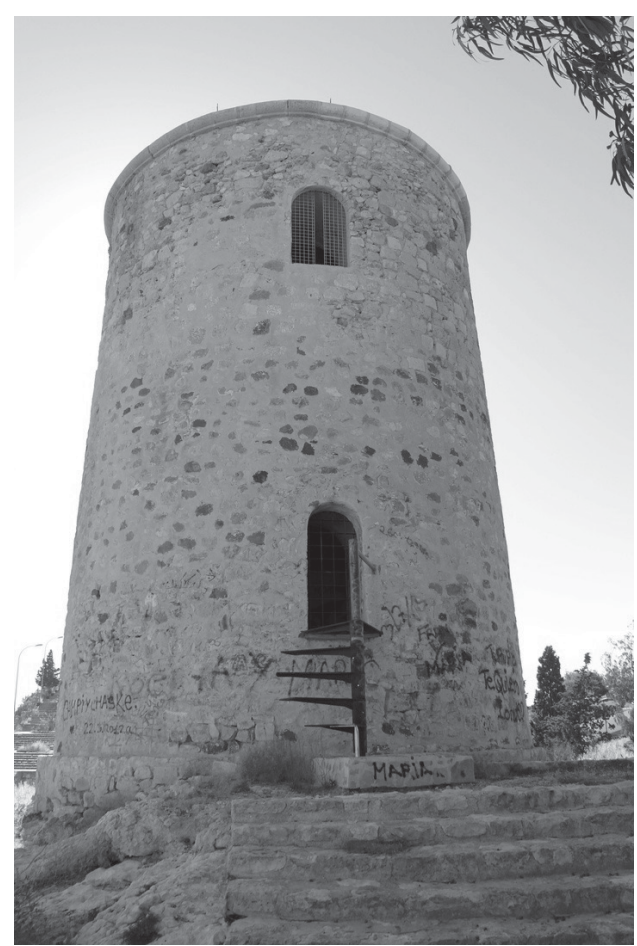

Fig. 6. Torre de Santa Isabel. 1579. Puerto de Mazarrón (Mazarrón). Realizada por Braulio Pérez Lizán. Acuña en el año 1534 señalaba que aún no se encontraba finalizada. Las obras debieron de quedar terminadas en el año 1579, tal y como recoge el corregidor Jorge Manrique y el capitán Juan de Molina en la visita que hicieron en la costa en mayo de ese mismo año ${ }^{59}$.

No se vuelven a tener documentos hasta finales del siglo XVIII, cuando el ingeniero Mateo Vodopich describe la torre de la siguiente manera:

Esta se halla en el día abandonada, pero no obstante su abandono, se conservan las paredes principales sin esencial detrimento; las bóbedas están 
bastantes quebradas, especialmente la superior y componer la inferior; hacer el parapeto de ladrillo; y reparar el caracol; se han de rebocar todas las paredes por dentro y por fuera y hacer varios reparos en todo el interior de ella para su uso, que todo junto con una puerta principal y otra para la salida de la batería se considera que poco más o menos podría importar unos 10,000 reales de vellón ${ }^{60}$.

Vodopich opinaba que la torre de Santa Isabel podría servir de utilidad para vigilar las zonas que San Idelfonso no podía realizar por su posición. Planteaba dotarla con cañones de 4 onzas de calibre montadas en cureñas de marina, con una dotación de un alcaide y dos torreros como miembros de la guarnición ${ }^{61}$.

Durante el siglo XVIII el edificio sufrió de numerosas modificaciones, tales como el vaciado del relleno de su interior y la apertura de una nueva a puerta a una altura de 1.4 metros del suelo. En los siglos XIX y XX su estado fue empeorando, presentando algunas deficiencias, tales como la carencia de algunos sillares en su cornisa y la desaparición de su antepecho en la terraza y del remate en su escalera ${ }^{62}$.

En mayo de 1990 se realizó bajo la dirección del Servicio de Patrimonio Histórico como proyecto para la completa restauración de la torre de la Cumbre las siguientes intervenciones.

- La recuperación del antiguo acceso mediante una escalera de caracol de acero fundido para soportar las condiciones tanto climáticas como marítimas de la zona y del nivel original del primer piso mediante una relesa.

- La restauración y protección de la cubierta, que se realizó con la colocación de una trampilla corredera ${ }^{63}$.

En general la restauración fue aceptable, pues la torre recuperó su antigua forma del siglo XVIII, restaurando su antepecho y facilitando la entrada a su inte- 
rior gracias a la escalera. Se construyó una valla de hierro para separar el entorno del bien con el resto del espacio urbano. Sin embargo, dicho elemento de separación no ha sido suficiente para evitar actos de vandalismo, entre los que se incluye la tira de vertidos y la realización de pintadas en sus muros. Siendo su solución la eliminación tanto de sus vertidos como de las pintadas utilizando métodos semejantes utilizados en otras torres como en el Molinete y reforzar la valla de separación.

\subsubsection{Torre de Navidad}

Localizada en los alrededores del soto de la Podadera, al sur del Monte de Galeras, junto al faro de Navidad y el Fuerte de Navidad en Cartagena ${ }^{64}$.

Su construcción respondía a la recomendación de Nicolás de Guevara en 1503 de fortificar la bocana del puerto de la ciudad de Cartagena. Es junto al castillo de la Concepción una de las edificaciones defensivas de mayor antigüedad que se conservan para la defensa del puerto cartagenero. Es de planta hexagonal, respondiendo a los modelos propuestos por Antonelli para la edificación de torres por las costas del Reino de Murcia ${ }^{65}$.

Presenta un diámetro interior de unos 12.80 metros y unos 11.00 metros entre sus caras opuestas, el espesor de sus muros es actualmente de 2.35 de grosor debido al deterioro constante a lo largo del tiempo. Los materiales empleados para la construcción de sus paredes son mampostería de piedra labrada e hiladas de aparejo de ladrillo ${ }^{66}$.

La torre presenta la ventaja de su localización, donde dominaba la entrada al puerto y batir la plaza en caso de caer en manos enemigas. Igualmente, su acción en

64 A. GÓMEZ VIZCAÍNO; D. MUNUERA NAVARRO; J. A. MARTínEZ LÓPEZ, «Catálogo de fortificaciones y baterías», Estudio y catalogación de las Defensas de Cartagenay su Bahía, J. A. MARTÍNEZ LÓPEZ (coord.), Comunidad Autónoma de la Región de Murcia, Consejería de Educación y Cultura, Dirección General de Cultura, 2002, p. 358.

65 A. GÓMEZ VIZCAÍNO; D. MUNUERA NAVARRO, «El sistema defensivo de los Austrias» en, Estudio y Catalogación de las Defensas de Cartagena y su Bahía, J. A. MARTíNEZ LÓPEZ (coord.), Comunidad Autónoma de la Región de Murcia, Consejería de Educación y Cultura, Dirección General de Cultura, 2002, p. 162.

66 J. F. GARCÍA VIVES; P. E. COLLADO ESPEJO, «Las Torres Vigías y Defensivas de Felipe II en la Región de Murcia. Análisis Integral y Propuesta de Recomposición y Musealización de la Torre Navidad» en XXIV Jornadas de Patrimonio Cultural de la Región de Murcia, T. ABELLÁN AGUILLAR (Coord), 2018, p. 102. 


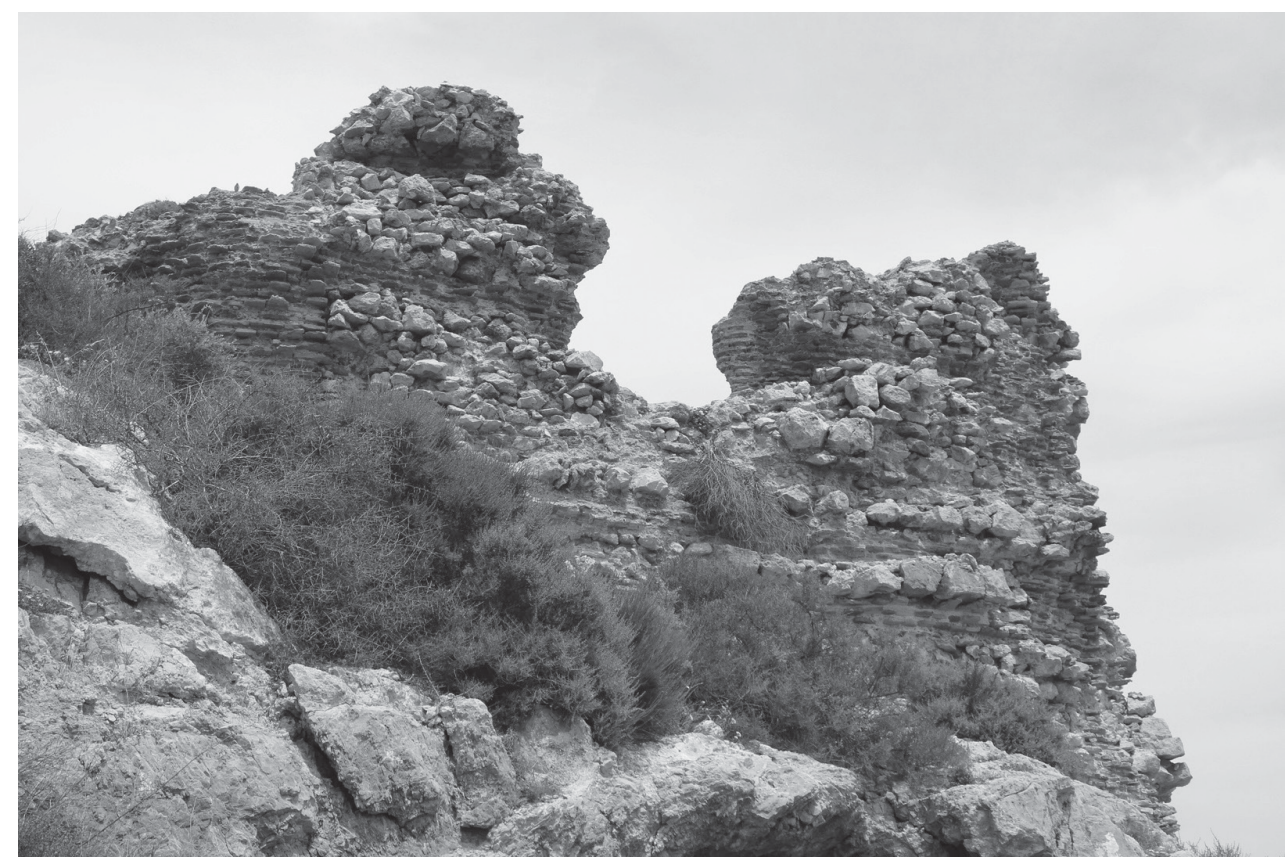

Fig. 7. Torre de Navidad. Circa siglo XVI-XVII. Ciudad de Cartagena (Cartagena). Realizada por Braulio Pérez Lizán.

caso de ocupación de la ciudad se vería dificultada por encontrarse con un gran cerro a su alrededor. Contaba con 5 troneras para los cañones capaces de soportar piezas de artillería ligera, siendo útil únicamente para su autodefensa, el impedimento de desembarco de tropas en sus inmediaciones, y de batir aun con dificultad la plaza central ${ }^{67}$.

Las obras de construcción comenzaron tras la visita del marqués de los Vélez al puerto de Cartagena el día 1 de enero de 1626, donde menciona:

La ciudad dijo que de la vizita que el señor marqués de los Beles a hecho, asi en ella como en su puerto y desenbarcaderos que los enemigos tienen en las partes de levante y poniente más sercanos a él, entre las cosas más conbinientes

67 Ficha de Catalogación: Arquitectura defensiva: delimitación de entornos de protección B.I.C. de la Región de Murcia, Archivo documental del servicio de patrimonio histórico de la Región de Murcia, p. 2 y A. GÓMEZ VIZCAÍNO, Op. cit., p. 163. 
para sudefensahallaquela sonelfabricarsedos cubosen laspuertasdeldicho su puerto [...] y una torre entre las dos Algamecas que están en la parte del poniente[.] ynpidiran los desembarcaderos y entradas de enemigos en este puerto $^{68}$.

Según el marqués de los Vélez, las defensas que ofrecía la muralla eran insuficientes y que ampliarla sería demasiado caro; remarcando que el precio de las torres y demás elementos sería bastante económico, y que en caso de falta de capital se podría utilizar del dinero prestado para las reparaciones de las murallas ${ }^{69}$.

El concejo de la ciudad aceptó el proyecto que el Marqués de los Vélez escribió una carta al rey Felipe IV con la propuesta. La respuesta del monarca no llegó hasta el 9 de junio de 1626, aceptando las propuestas de construcción de dichos edificios, con la excepción de no utilizar el dinero destinado a la reparación de la muralla de Cartagena y para la construcción de dos torres localizadas en Cabo Cope y Calabardina, pertenecientes al ayuntamiento de Lorca y posteriormente Mazarrón. Sin embargo, el Marqués de los Vélez ignoró dicha orden real con el motivo de que el monarca observaría de buen grado las actuaciones que se llevaran a cabo y que ninguna fábrica de murallas puede ser de tanta ynportancia como las dichas dos torres en la boca del dicho puerto ${ }^{70}$.

Las obras de construcción obras se detuvieron en 1627 por diversos motivos, entre ellos el trasladó de su promotor, el IV Marqués de los Vélez a Valencia y una real carta fechada el 7 de marzo de 1627 preguntando sobre el estado de las murallas que debían de ser reparadas con el dinero que se les fue prestado y que fue utilizado para la construcción del primer cuerpo de la torre ${ }^{71}$.

La edificación fue posteriormente abandonada sin llegar a ser finalizada y posiblemente sus materiales fueran utilizados para la construcción de otros edificios, como las baterías de Trincabotijas y la Podadera y el fuerte de Navidad siendo a la

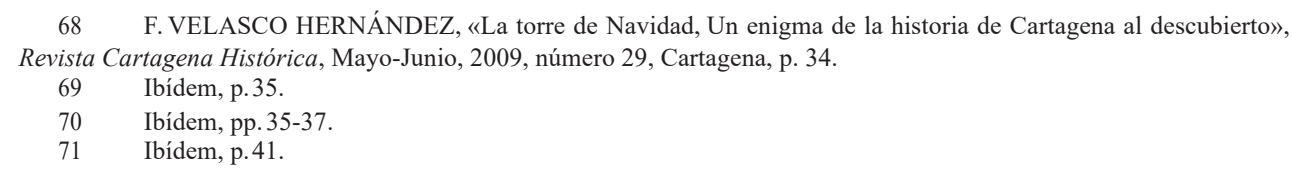


vez extraño que no se demoliera por completo. No se observa ningún elemento de conservación y protección, haciendo que la vegetación y los efectos del clima y el mar aceleren su deterioro. La torre ha perdido su revestimiento de cal que seguramente tendría en la mampostería, los ladrillos de las esquinas y las jambas presentan un alto grado de disgregación y perdida de volumen, causando que los muros apenas tengan la mitad de altura que tendrían en origen. Por lo tanto, es necesario la intervención inmediata, procediendo a realizar un análisis detallado acerca del estado de los restos existentes y la cuidadosa eliminación de la vegetación, planteándose para su rehabilitación diversos criterios y metodologías, enfocados en la recuperación, puesta en valor y potenciación de la construcción como un recurso cultural ${ }^{72}$.

\subsection{Torres Post-litorales}

También se ven incluidas en el siguiente artículo las denominadas según por el Plan Nacional de Arquitectura Defensiva como torres pertenecientes a las casas fuertes o post-litorales según explica Rubio Paredes. Al contrario que las torres de defensa de la costa, que eran de mayor tamaño, con mejores materiales y construidas por las autoridades con fondos públicos para proteger los puntos más accesibles del litoral; estas torres fueron edificadas por terratenientes y nobles. Se encontraban en asentamientos agrícolas y ganaderos cerca del litoral como partes de un complejo urbanístico resistente y con carácter defensivo cuya misión era vigilar el territorio adyacente, advertir sobre la presencia de corsarios en la zona y proporcionar un lugar de resistencia a sus habitantes ${ }^{73}$.

Por la zona ribereña se levantaron algunas de estas edificaciones quedándose en ella numerosos topónimos. Dando a entender que fueron edificios habituales en las zonas rurales y que con el paso del tiempo fueron el origen de agrupaciones vecinales y posteriormente pedanías. Entre las torres que existían por la zona costera de Murcia destacan: torre Muchuela, torre Saavedra, torre Silva, torre Blanca, torre Siles, torre Octavio, torre Rubia o ElCastillico ${ }^{74}$.

\footnotetext{
72 Ficha de Catalogación: Arquitectura defensiva: delimitación de entornos de protección B.I.C. de la Región de Murcia, op cit, p: 3, 162-163 y J. F. GARCÍA VIVES; P. E. COLLADO ESPEJO, Op cit, pp: 102-103.

73 J. M. RUBIO PAREDES, Op cit, p: 29.

74 S. ALONSO NAVARRO, Op. cit., p. 137 y G. JIMÉNEZ DE GREGORIO, Op. cit., p. 46.
} 


\subsubsection{Torre delRame}

También denominada como la torre del Rami.Se localiza en los Alcázares a unos pocos metros del Mar Menor. Presenta unos orígenes que se remontan a época romana, pues en la zona sur de dicha torre aparecieron diversos fragmentos cerámicos vinculados a una antigua villa. Las continuas roturaciones de la tierra han dificultado la búsqueda de sus restos materiales ${ }^{75}$.

Se trata de una edificación de estructura cuadrada de unos 9 metros. Presenta tres plantas con terraza almenada. Existen en la primera planta varias estancias separadas por muros a media altura, en el segundo se ubica un palomar y en la última planta sólo se encuentra una pequeña estancia. En todos los pisos, el techo se encuentra cubierto por una bóveda de cañón. En la fachada norte se ubican dos balcones y debajo la puerta de ingreso a la torre, donde además se localiza encima de ella el escudo que construyó la edificación, los Bienvengurd. En su parte sur seencuentran dos pequeñas ventanas con marcos de madera ${ }^{76}$.

Gracias a la obra de Alfonso X el Sabio Libro de Repartimiento de Murcia se han conservado una serie de nombres de origen musulmán, en el caso de Rame proviene de la denominación Faraich Arramin, cuya traducción sería de Faray el Ballestero.

En la obra de Alfonso X cita que dicha torre fue cedida a Ponz de Villanueva en la partición de las tierras o rahalaes del campo de Cartagena en el año 1268. Pues al ser ocupada los territorios de la actual Murcia a manos de Fernando de Aragón y cedida posteriormente a Alfonso X.

La torre del Rame (o del Ramí) se convirtió durante el siglo XVI en un señorío jurisdiccional, una porción de tierra segregado del estado cuyo señor poseía diversos poderes tales como el jurisdiccional, económico y defensivo. Fue uno de los

75 AA.VV, Los Alcázares en el Contexto de la formación de la comarca del Mar Menor, Vol I, Universidad de Murcia, 2008, p.25.

76 Ficha de catalogación de bienes de interés cultural de la Torre del Rame, Archivo documental del servicio de Patrimonio Histórico de la Región de Murcia, Consejería de Cultura y Portavocía Dirección General de Bienes Culturales, Murcia, pp.1-2. 


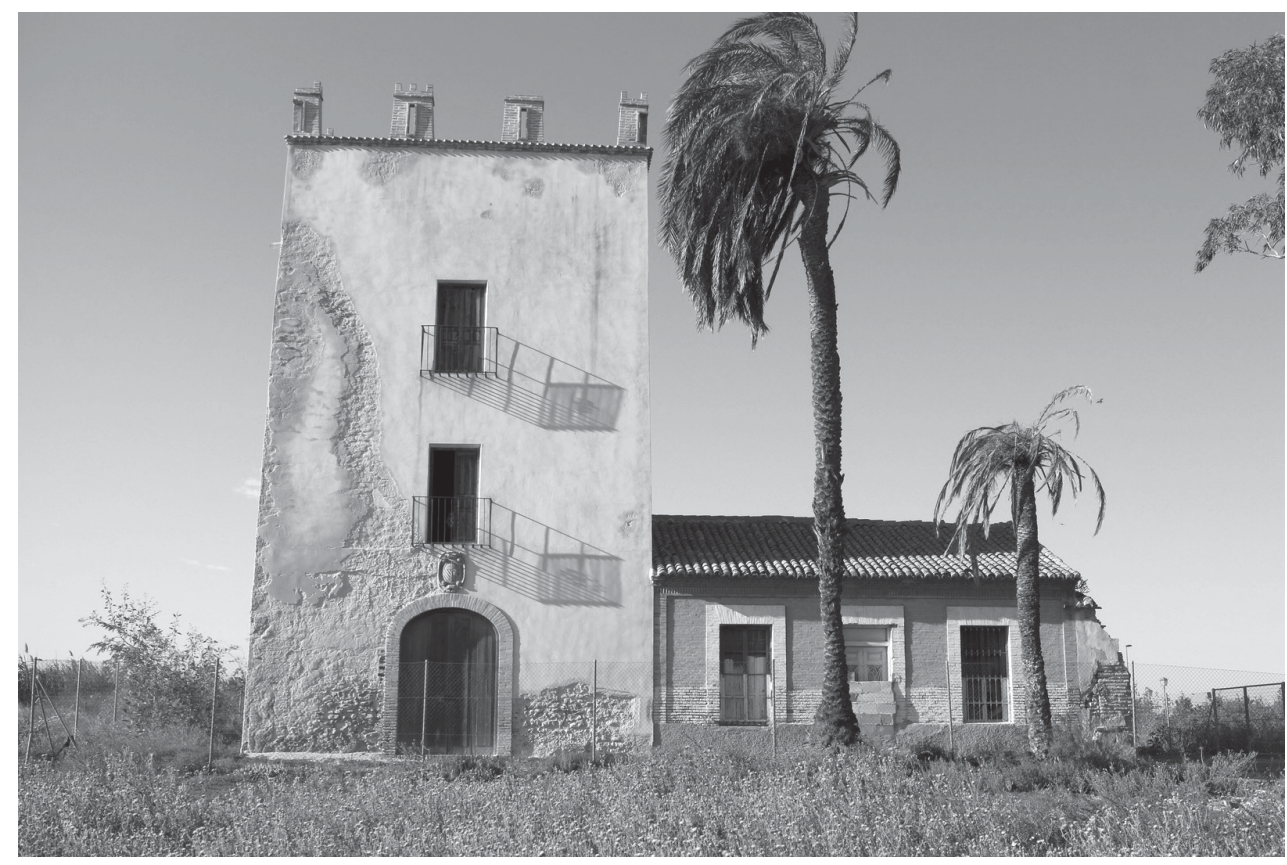

Fig. 8. Torre del Rame. Circa siglo XVI-XVII. Los Alcázares. Realizadas por Braulio Pérez Lizán.

muchos de los señoríos que nacieron dentro del Concejo Murciano ${ }^{77}$. Sus orígenes se deben a un censo de principios del siglo XV que pasó a diversas familias, como la Abellán, Guzmán, hasta Nicolás Gari, miembro con prebendado de la catedral de Murcia que la adquirió en 1541. En 1591 es cedida al cabildo catedralicio y un año después vendió la hacienda a Diego de Bienvengud Rosique III, corregidor de Cartagena e iniciando un proceso de acaparamiento de tierras del Ramí y Hoya Morena.

En 1607 su hijo, Nicolás Bienvengud de Lizana amplió la haciendo del Rame describiendo su propiedad con una iglesia y 6 caseríos, con escasez de montes, árboles y agua, pero bien vigilada por la presencia de las torres. En 1623 detalla que el señorío de Villa Morena y el Rami presentaba diversas edificaciones, entre ellas unaiglesia, huerta, noria y la casa principal con torre. La presencia del linaje cartagenero se prolongó hasta principios del siglo XVIII, siendo sustituida por un nuevo linaje familiar, 
los Fontes, que durante el siglo XVII comenzaron a ocupar las tierras pertenecientes a los Bienvengud ${ }^{78}$.

Durante el siglo XIX, zonas como las del Rami se van despoblando, en principal medida por la cierta seguridad que comienza a florecer por las costas murcianas. La torre del Rame cambia constantemente de dueños hasta que en los años 1920 pasa a la familia Martínez Rosique, siendo su actual dueña María José Martínez Lamberto.

El edificio sufrió numerosas modificaciones según las necesidades de sus dueños, como la sustitución del almenado del siglo XVII por uno nuevo en los años 50, así como la construcción de diversas estancias para el almacenaje de ganado y cereales.

Durante finales del siglo XX y principios del XXI las tierras adyacentes a la torre se convirtieron en un complejo urbanístico y un campo de Golf ${ }^{79}$. Fue también dicha época cuando se realizaron diversas intervenciones de restauración, tanto en la fachada como en el interior, en especial en las bóvedas, arcos, etc. Sin embargo, dichas intervenciones se ven gravemente comprometidas por la mala calidad del material empleado, sumándose además los constantes ataques de vandalismo queha sufrido el interior de la torre por la escasez de medidas de seguridad, encontrándose gravemente dañadas la escalera central, las bóvedas, la zona del palomar en la segunda planta y unos grabados y unas pinturas que representan animales y navíos.

Las medidas a tomar serían la restauración de los elementos dañados por los actos de vandalismo y de las intervenciones realizadas en el pasado, la incorporación de medidas de seguridad más contundentes y la limpieza del terreno de escombro y vertidos. Otro aspecto a destacar es la pérdida del paisaje original en donde se encuentra la torre, ya que, cuando comenzaron las obras la Ley de Patrimonio de Murcia y el Plan Nacional aún no estaban publicados y la ley de Patrimonio Español no define correctamente la delimitación del entorno que debe ser protegido.

\footnotetext{
78 Ibídem, pp. 168-171.

79 AA.VV,Los Alcázaresalolargodelossiglos XIXYXXX.Pasadoypresentedeunnuevomunicipio, VolII, Universidad de Murcia, 2008,p. 394.
} 


\subsubsection{Torre delNegro}

Ubicado en el término de los Urrutias, perteneciente al ayuntamiento de Cartagena. Antiguamente denominada como la torre del Arraez. La razón del cambio de nombre al de torre del Negro fue al color de la piel de un esclavo de las galeras reales que trabajó la finca, provocando que la rebautizaran como la torre del Negro ${ }^{80}$.

Su construcción fue realizada durante el año 1585 según la lápida de mármol en la puerta de acceso: Reinado de la meg. Del don Felipe Sr. Do desde. Juan Giner pagador de sus Armadas y Galeras y Regidor de Cartagena, Mando hacer esta torre 1585.

Las medidas de la base son de 8.25 metros en sus lados norte-sur y de 8.15 en la parte este-oeste, con unos muros de 1.5 de grosor. Adosada a la torre seencuentra una casa de campo que se apoya en su muro oeste.

La primera planta presenta una puerta en su zona sur abierta en época contemporánea. La entrada al segundo nivel se encuentra en la cara norte con un balcón al oeste que antiguamente fue una primitiva ventana enrejada. El tercer piso presenta una disminución de tamaño debido a la inclinación del torreón, con una ventana alargada en su cara norte y tres ventanas repartidas por las partes sur, este y oeste.

Tras la primera planta, el edificio muestra un cambio de materiales por otros más livianos, como el ladrillo de arcilla y yeso. El segundo piso presenta unos materiales semejantes a la primera, aunque disminuye el espacio debido a la inclinación de sus paredes. Sobre la tercera planta se situaba la azotea, que primitivamente debió ser de arcilla, madera y caña.

Sobre esta cubierta se sitúan las almenas de ladrillo cocido y dispuestas escalonadamente en forma de pirámides, creando así una crestería de adorno realizadas en fechas posteriores a la construcción de la torre. En su interior los techos tenían que estar cubiertos por bóvedas de cañón, aunque en la actualidad solo se conserva en la primera planta ${ }^{81}$.

\footnotetext{
80 S. ALONSO NAVARRO, Op. cit., p. 139.

81 Ibídem, pp. 138-139.
} 


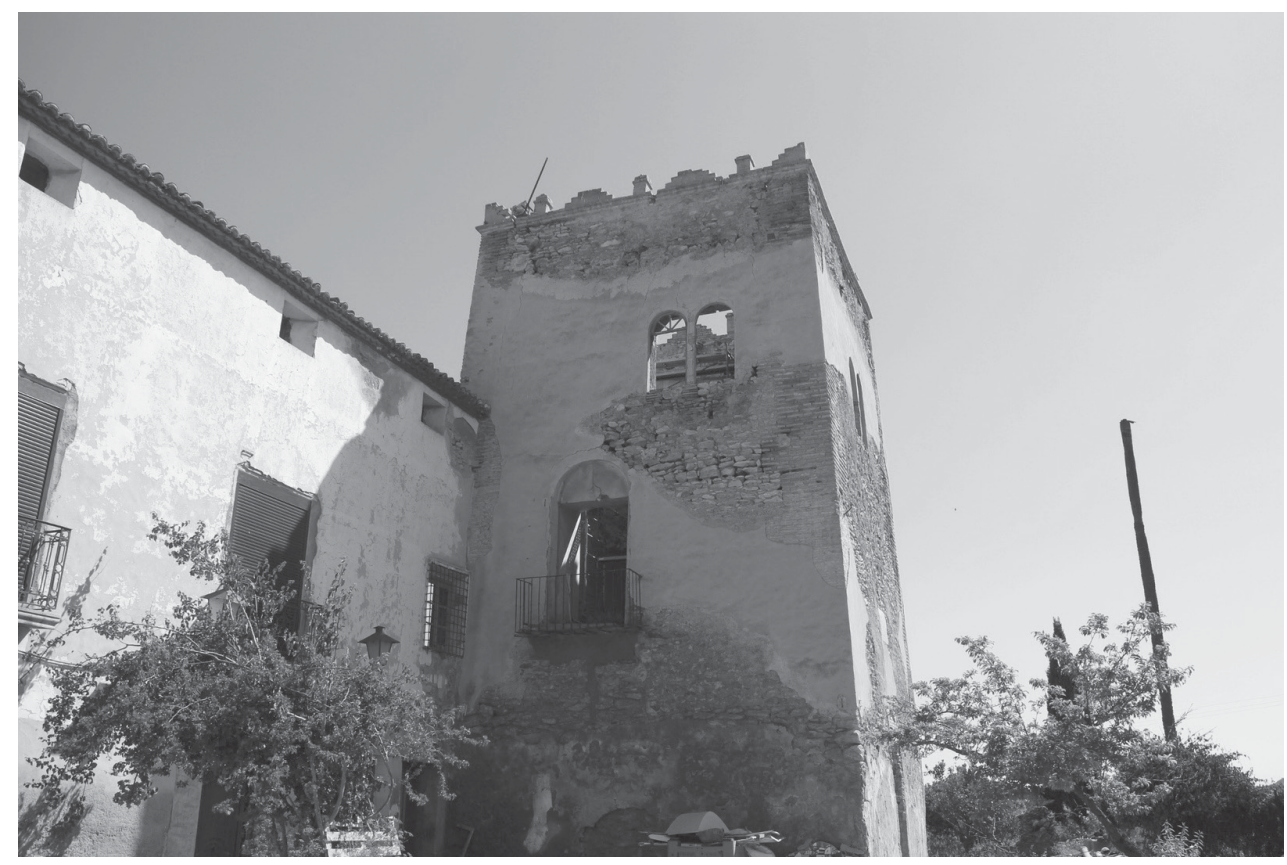

Fig. 9. Torre del Negro. 1585. Los Urrutías (Cartagena). Realizada por Braulio Pérez Lizán.

El estado del bien, según los informes realizados por el Servicio de Patrimonio en la década de los 80 era de ruinoso y con necesidad de intervención urgente. Debido a que diversos agentes externos tales como el hombre y el clima provocaron la desaparición de ciertas partes de la torre, entre las que destacan el suelo del piso superior. Con su caída, las bóvedas que se encontraban en el tercer y segundo piso se destruyeron.

En la actualidad, su estado ha empeorado, ya que todavía mantiene los problemas citados anteriormente.

A pesar de ello se puede observar que la estructura muestra una enorme solidez, sin que se observen fisuras o grietas debido a su forma de pirámide truncada de base cuadrada, que evita el desplome de sus muros ${ }^{82}$. Las medidas a tomar para 
su restauración y conservación siguen pendientes entre la consejería de educación y cultura, el ayuntamiento de Cartagena y el propietario.

\subsubsection{Torre de Oviedo}

Fue construida por el mercader Nicolás Toya Monserrate en 1678 aunque más tarde pasaría a la familia de los Oviedo del que toma su nombre, como una de las numerosas casas-refugios con torres construidas por todo el litoral murciano en el siglo XVIII ${ }^{83}$.

Denominada también como la Torre del Chichao, se encuentra entre las localidades de la Puebla y los Urrutias, perteneciente al ayuntamiento de Cartagena. También se le denomina por error como torre Aredo, dicha equivocación o falsedad pudo deberse a la transcripción de algún topógrafo participante en el levantamiento de la planimetría de la zona ${ }^{84}$.

Es un edificio de planta rectangular adosado a una vivienda dentro de una unidad agrícola con aljibe, patio y dependencias anexas, formándose así un complejo que se adapta al entorno. La torre muestra una visión "monolítica" que, junto a sus pequeñas aperturas le otorgan una sensación de fortaleza. Sus dimensiones en exterior son de 6.1 X 7.3 metros. Su construcción es a base de muros de mampostería de piedra caliza sin carear y mortera de cal para los elementos verticales, utilizando vigas de madera para los horizontales. En las esquinas se puede apreciar diversos materiales tales como el ladrillo, bastante comunes en otras construcciones. Las bóvedas del primer piso se realizaron a base de colañas de piedra. El techo de la segunda planta se encontraba realizado a base de vigas de madera con aspecto de rollizos sin elaboraciones $^{85}$.

\footnotetext{
83 Hispania Nostra: Lista Roja de Patrimonio: Torre de Oviedo, Publicado el 27 de Julio de 2018, Consultado en http://listarojapatrimonio.org/ficha/torre-de-oviedo/ el 25 de Octubre de 2018.

84 Ficha de Catalogación: Casas fuerte del Campo de Cartagena: Torre de Oviedo, Archivo documental del servicio de Patrimonio Histórico de la Región de Murcia, Murcia, p.3.

85 Ibídem, pp.4-6.
} 


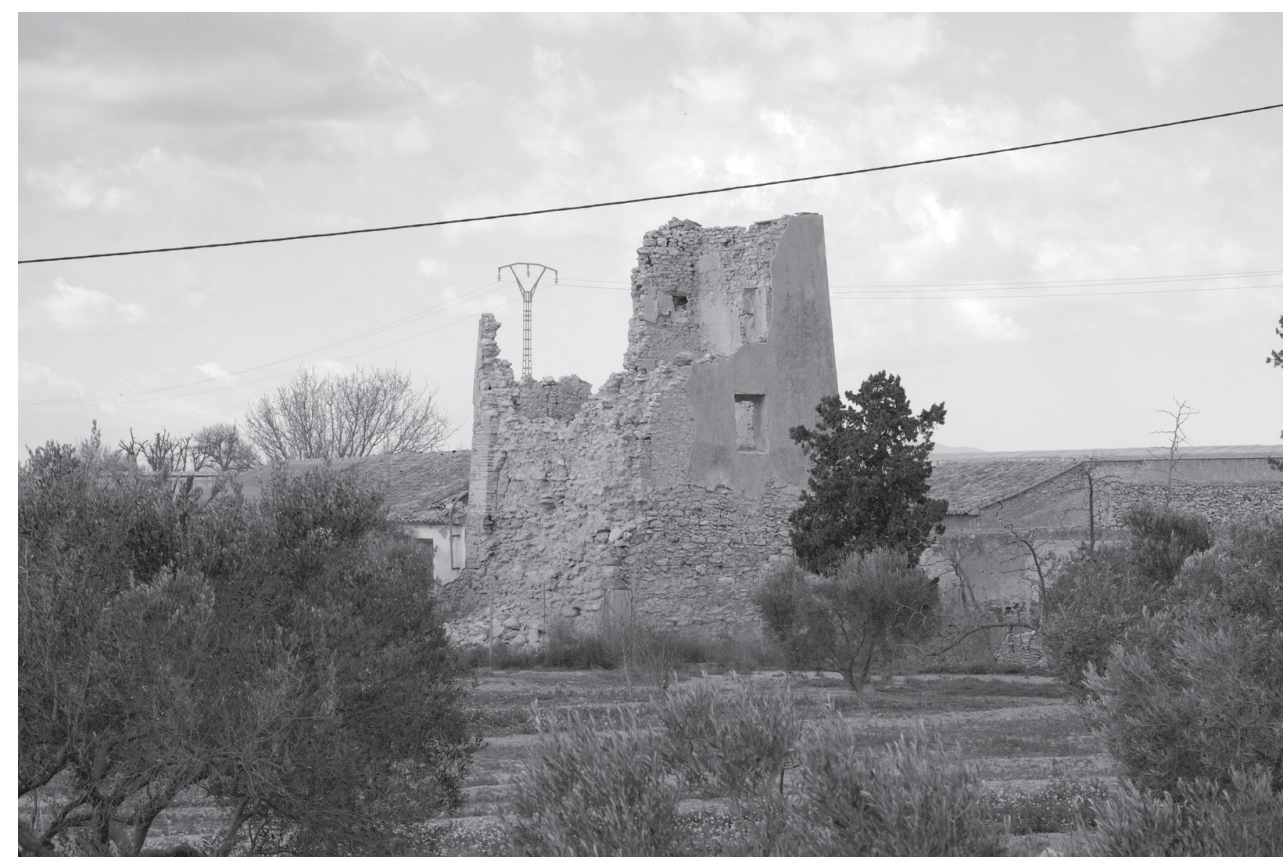

Fig. 10. Torre de Oviedo. Circa siglo XVII. La Puebla (Cartagena). Realizada por Braulio Pérez Lizán.

En la actualidad la torre se encuentra en pésimas condiciones, debido a la falta de medidas de prevención y conservación. Causando que parte del cuerpo superior del edificio se desplomara, desapareciendo así su terraza y almenado.

\section{Conclusiones}

Analizadas las causas de porque los países cristianos colindantes al Mar Mediterráneo se vieron en la necesidad de vigilar sus fronteras marítimas, custodiándolas de posibles peligros ya que a pesar de que el desafío de expansión turca fue detenido tras la batalla de Lepanto, no fue así con otras clases de amenazas provenientes de los países musulmanes, especialmente la piratería. Ésta tuvo su época de esplendor a partir del final del siglo XVI y provocó numerosos problemas y desastres por toda la costa. Las naciones que sufrieron las constantes llegadas de estos incursores se vieron 
en la necesidad de tomar medidas de prevención y defensa entre las que destacan la construcción de elementos de vigilancia y defensa, entre los que se puede mencionar los castillos, atalayas, baterías o el tema del trabajo, las torres vigías.

En el caso del Reino de Murcia, la construcción de estas edificaciones vino durante la Baja Edad media y Carlos V, pero fue con Felipe II quién viendo en su reinado que los ataques a sus costas eran más constantes se vio en la necesidad de erigir estas torres para vigilar sus costas y dar seguridad y protección a sus habitantes. Los proyectos llevados a cabo a manos por Juan Bautista Antonelli y Vespasiano Gonzaga fueron los responsables de que las costas de Murcia estuvieran protegidas con dichas construcciones. Es también importante mencionar la edificación de las torres privadas a manos de los miembros de la alta clase.

Su eficacia fue cuestionable pues a pesar de que eran una molestia para los piratas, no evitaba su llegada a las costas y provocaran desastres y secuestros entre la población costera. Incluso fueron consideradas como un estorbo por los concejos de Murcia, Cartagena y Lorca.

Durante el siglo XVIII y XIX las torres perdieron su utilidad y muchas de ellas se vieron desmanteladas como las torres de San Idelfonso en Mazarrón, Cabo de Palos y Portman en Cartagena, y la de la Encañizada y el Estacio en San Javier.

Las pocas que se conservan actualmente en la Región de Murcia sufrieron del deterioro constante por su falta de uso, llegando a encontrarse en ruinas de no ser por la intervención de las diversas unidades administrativas y los múltiples programas y leyes que regulan las medidas a tomar, entre ellas la Ley16/85 de Patrimonio Histórico Español, la ley 4/2007 de Patrimonio Histórico de la Región de Murcia y El Plan Nacional de Arquitectura Defensiva. A pesar de todo, estas medidas de conservación y restauración no se han podido realizar en la actualidad en las torres privadas repartidas por el litoral de Murcia. Encontrándose muchas de ellas en un estado irreconocible, ya sea por la modificación agresiva de sus dueños o el abandono total de ellas. Quedando en algunos casos destruidas y en ruinas.

La difusión y protección de las torres vigías es un tema que la población 
debe de tener en cuenta, pues gran parte de la sociedad actual no es consciente de la importancia que tenían a lo largo de la historia de Murcia. Son un reflejo del pasado, del peligro que las costas presentaban al ser Murcia una zona de avistamiento y desembarco de piratas. Son las causantes de la fundación de algunos de los centros de población que existen hoy en día. Su importancia fue tal que se encuentran representados en los escudos de algunas ciudades, ya que otorgaron seguridad y protección a sus pobladores como en el caso de los escudos de as ciudades de San Pedro del Pinatar o San Javier. 